\title{
Fluorescence of Chlorophyll $a$ during Seasonal Water Stratification in the Black Sea
}

\author{
N. A. Moiseeva ${ }^{1, *}$, T. Ya. Churilova ${ }^{1}$, T. V. Efimova ${ }^{1}$, O. V. Krivenko ${ }^{1}$, \\ D. N. Matorin ${ }^{2}$
}

${ }^{1}$ A. O. Kovalevsky Institute of Biology of the Southern Seas, Russian Academy of Sciences, Sevastopol, Russian Federation

${ }^{2}$ Lomonosov Moscow State University, Moscow, Russian Federation

* nataliya-moiseeva@yandex.ru

Purpose. At present the express method of estimating the chlorophyll $a$ concentration by its fluorescence is widely spread. The applied in calculations coupling coefficient between these two values is assumed to be constant (in time and space); but it does not correspond to reality. Therefore, the basic purpose of the paper consists in studying dependence of fluorescence on the chlorophyll $a$ concentration in the deep part of the Black Sea in a warm period when seasonal water stratification is observed.

Methods and Results. Relation between the light absorption by the phytoplankton pigments, and the chlorophyll $a$ concentration and fluorescence is investigated. It is shown that the ratio between the chlorophyll $a$ concentration and fluorescence was different in the quasi-isolated layers during the seasonal water stratification. Revealed is the vertical heterogeneity of fluorescence normalized for the chlorophyll $a$ concentration in the euphotic layer. It is conditioned by change of the phytoplankton ability to absorb light quanta at the wavelength $\sim 455 \mathrm{~nm}$ (fluorescence excitation) calculated for a unit of the chlorophyll $a$ content. Comparison of the specific values of fluorescence and light absorption index on the wavelength $\sim 455 \mathrm{~nm}$ showed their strong mutual correlation that testifies to insignificant variation of the values of the fluorescence quantum yield within the photosynthesis zone. Conclusions. The obtained dependences between the chlorophyll $a$ concentration and fluorescence can be used to specify the algorithms applied at present for reconstructing the chlorophyll $a$ concentration profiles based on the data of either the fluorescence submerged probes or the drifting floats of the international project Biogeochemical Argo.

Keywords: chlorophyll $a$, fluorescence, light absorption, quantum yield, phytoplankton, the Black Sea.

Acknowledgments: the research is carried out according to the state order No. AAAA-A18118020790229-7, theme "Study of Spatial-Temporal Organization of Aquatic and Land Ecosystems Aimed at Development of Operational Monitoring System based on the Remote Sensing Data and GIS Technologies" No. AAAA-A19-119061190081-9 and theme "Comprehensive Studies of the Current State of the Ecosystem of the Atlantic Sector of the Antarctic" as well as under the partial RFBR support, grants No. 17-05-00113 and 18-45-920070. The authors are very thankful to the expedition head A. S. Mikaelyan and to the group of hydrological research, S. A. Shutov and P. O. Shapovalov, for their arrangement of research.

For citation: Moiseeva, N.A., Churilova, T.Ya., Efimova, T.V., Krivenko, O.V. and Matorin, D.N., 2019. Fluorescence of Chlorophyll $a$ during Seasonal Water Stratification in the Black Sea. Physical Oceanography, [e-journal] 26(5), pp. 425-437. doi:10.22449/1573-160X-2019-5-425-437

DOI: $10.22449 / 1573-160 \mathrm{X}-2019-5-425-437$

(C) 2019, N. A. Moiseeva, T. Ya. Churilova, T. V. Efimova, O. V. Krivenko, D. N. Matorin

(C) 2019, Physical Oceanography

\section{Introduction}

The use of chlorophyll $a(F)$ fluorescence measurements in hydrobiological studies counts an almost century-old history [1, 2]. The Biogeochemical-Argo (BGC-Argo) drift float research program has been launched in the Black Sea since 2008 (http://biogeochemical-argo.org/). Currently, BGC-Argo floats measure only one biological parameter - chlorophyll $a$ fluorescence. Recalculation of 
the fluorescence $F$ values recorded applying BGC-Argo floats in the Black Sea into the concentration values of the main photosynthetically active pigment chlorophyll $a\left(C_{a}\right)$. It is carried out using the algorithm [3], created for Case 1 waters according to the optical classification. However, the Black Sea belongs to the Case 2 waters [4]. The algorithm suggested in [5, p. 8] assumes a constant coefficient of proportionality in relationship between $C_{a}$ and $F$.

It is known that the chlorophyll $a$ fluorescence intensity $F\left(\mu \mathrm{E} \cdot \mathrm{m}^{-3} \cdot \mathrm{s}^{-1}\right)$ under the natural conditions of the existence of phytoplankton depends on several parameters [6, p. 242]:

$$
F=P A R \cdot C_{a} \cdot \bar{a}_{\mathrm{ph}}{ }^{*} \cdot Q_{a}^{*} \cdot \varphi_{\mathrm{F}},
$$

where $P A R$ is photosynthetically active radiation (PAR) in the range from 400 to $700 \mathrm{~nm}, \mu \mathrm{E} \cdot \mathrm{m}^{-2} \cdot \mathrm{s}^{-1} ; \quad C_{a}$ is the chlorophyll $a$ concentration, $\mathrm{mg} \cdot \mathrm{m}^{-3} ; \bar{a}_{\mathrm{ph}}{ }^{*}$ is the average spectrum value of the specific (normalized to $C_{a}$ ) coefficient of light absorption by phytoplankton pigments $\left(a_{\mathrm{ph}}^{*}(\lambda)\right), \mathrm{m}^{2} \cdot \mathrm{mg}^{-1} ; Q_{a}^{*}$ is fluorescence intracellular reabsorption factor; $\varphi_{\mathrm{F}}$ - quantum yield of fluorescence in vivo.

Value of the coefficient $a_{\mathrm{ph}}^{*}(\lambda)$, and consequently the value of $\bar{a}_{\mathrm{ph}}{ }^{*}$ vary by almost an order of magnitude, according to theoretical [7] and in situ [8] studies in the oceans. The quantum yield of fluorescence depends on the light intensity, nutrient availability and species composition of the phytoplankton community $[9,10]$. As can be seen from equation (1), the relationship between the parameters $F$ and ${ }^{\prime} C_{a}$ is far from straightforward and is due to the influence of the environmental factors on the phytoplankton functional characteristics: $a_{\mathrm{ph}}^{*}(\lambda)$ and $\varphi_{\mathrm{F}}$ [9]. In accordance with the results obtained during long-term studies in the Black Sea [11], values of $a_{\mathrm{ph}}^{*}(440)$ change 2-3 times between seasons (winter - summer). The influence of environmental factors on the values of $a_{\mathrm{ph}}^{*}(\lambda)$ and $\varphi_{\mathrm{F}}$ causes the variability of the relationship between the fluorescence $F$ and the chlorophyll $a$ concentration $C_{a}$ within the same water area during the year, when seasonal stratification divides waters into quasi-isolated layers.

In this regard, the present paper is aimed to study the dependence of fluorescence intensity $F$ on the chlorophyll $a$ concentration $C_{a}$ in the Black Sea in the warm season, when seasonal stratification of waters is observed.

\section{Methods}

The research was carried out in the deep-water part of the Black Sea (Fig. 1) during the $97^{\text {th }}$ scientific cruise of the R/V "Professor Vodyanitsky", October 2428, 2017. Water samples were taken from different depths of the euphotic layer using a cassette of Niskin bottles attached to the SBE-911plus probe (Sea-Bird Electronics). The depths were chosen based on the temperature, the chlorophyll $a$ fluorescence $(F)$ profiles, and the water transparency, assessed based on 
the Secchi disk (Zs) visibility depth. For the research aim implementation the sampling was executed at the depths within the following four layers:

1) the upper mixed layer (UML),

2) the thermocline (TC),

3 ) the layer between the thermocline and the depth of $1 \%$ of the PAR incident on the sea surface,

4) the layer between the depth of $1 \%$ and $0.1 \%$ of the PAR incident on the sea surface.

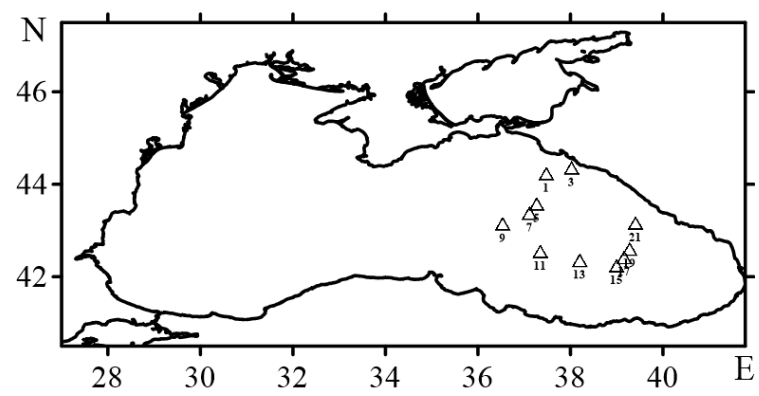

F i g. 1. Map of the stations $(\Delta)$ in the $97^{\text {th }}$ cruise of RV "Professor Vodyanitsky", October 24-28, 2017

The bottom of the $Z_{\text {eu }}$ photosynthesis zone was assumed to be at the depth, where photosynthetic available radiation (PAR) is $1 \%$ of its surface value. The $Z_{\text {eu }}$ values were assessed using the dependence of the diffuse light attenuation coefficient (for downwelling irradiance) on $Z_{\mathrm{s}}[12]$.

\section{Chlorophyll $a$ and phaeopigment concentration}

Seawater samples $(1.5 \mathrm{~L})$ were filtered through glass fiber filters $(\mathrm{GF} / \mathrm{F}$, Whatman) under low vacuum $(<0.2 \mathrm{~atm})$. Then the filters were folded twice (by the particles collected inward), wrapped in foil and stored in liquid nitrogen in a Dewar $\left(\mathrm{t}=-196{ }^{\circ} \mathrm{C}\right)$ until further measurement in the laboratory. Optical measurements were carried out with a double-beam spectrophotometer Lambda 35 (PerkinElmer).

Concentration of chlorophyll $a\left(C_{a}\right)$ and phaeopigments $\left(C_{\text {phae }}\right)$ was estimated by spectrophotometric method using the equations [13]:

$$
\begin{gathered}
C_{a}=\left[2,7\left(D_{\mathrm{o}}(665)-D_{\mathrm{a}}(665)\right) V_{\mathrm{E}}\right] / V_{\mathrm{F}} l, \\
C_{\text {phae }}=\left[2,7\left(1,7 D_{\mathrm{o}}(665)-D_{\mathrm{a}}(665)\right) V_{\mathrm{E}}\right] / V_{\mathrm{F}} l,
\end{gathered}
$$

where $D_{\mathrm{o}}(665)$ and $D_{\mathrm{a}}(665)$ are the optical density values at $665 \mathrm{~nm}$ wavelength before and after acidification of the pigment extract in acetone solution (90\%), respectively; $V_{\mathrm{E}}$ is the extract volume, $\mathrm{cm}^{3} ; V_{\mathrm{F}}$ is the water sample volume, $\mathrm{dm}^{3}$; $l$ is the cuvette optical path length, cm. In the present research $V_{\mathrm{E}}=5 \mathrm{~cm}^{3}$; $V_{\mathrm{F}}=1.5 \mathrm{dm}^{3}$ and $l=1 \mathrm{~cm}$. 


\section{Light absorption by particles, phytoplankton pigments}

The light absorption by a particles, phytoplankton pigments was estimated in accordance with the NASA protocol [14] using the filter pad technique ("wet filter technique") [15]. Optical density of the samples was measured at the wavelength from 350 to $750 \mathrm{~nm}$ using a dual-beam spectrophotometer Lambda 35 (PerkinElmer) equipped with an integrating sphere. The particulate light absorption coefficient was calculated by the following equation:

$$
a_{\mathrm{p}}(\lambda)=\left[2,3 \cdot O D_{\mathrm{p}}(\lambda) \cdot S\right] \cdot \beta(\lambda) / V
$$

where 2.3 is the conversion factor of $\lg$ to $\ln ; S$ is the filter "working" area, $\mathrm{m}^{2} ; V$ is the water sample volume, $\mathrm{m}^{3} ; \beta$ - correction of a difference in an optical path between the particles collected on the filter and particles suspended in water (Mitchell, 1995); $O D_{\mathrm{p}}(\lambda)$ is the optical density of the particles (collected on the filter) [16].

To separate the $a_{\mathrm{p}}(\lambda)$ coefficients into its components - light absorption by phytoplankton pigments $\left(a_{\mathrm{ph}}(\lambda)\right)$ and non-algal particles $\left(a_{\mathrm{NAP}}(\lambda)\right)$ - the sample was bleached by a solution of sodium hypochlorite $(\mathrm{NaClO})$ [17]. The $a_{\mathrm{ph}}(\lambda)$ value was calculated by the following equation:

$$
a_{\mathrm{ph}}(\lambda)=a_{\mathrm{p}}(\lambda)-a_{\mathrm{NAP}}(\lambda) .
$$

At all the stations, in addition to the fluorescence profile (the SBE-911plus probe data), fluorescence intensity was measured using a laboratory MEGA-25 fluorimeter with exciting radiation at the $\sim 455 \mathrm{~nm}^{1}$ wavelength. Before the measurements, seawater samples were adapted to darkness for 10-30 min [18] depending on the light intensity in the environment (light "history" of the phytoplankton existence). The following fluorescence parameters were measured: $F_{0}$ - the chlorophyll $a$ fluorescence intensity, measured when reaction centers (RC) of photosystem 2 are open, and $F_{\mathrm{m}}$ - the chlorophyll $a$ fluorescence intensity, when RCs are closed. $F_{0}$ and $F_{\mathrm{m}}$ are corresponding to constant and maximum fluorescence intensity ${ }^{1}$. These chlorophyll $a$ fluorescence parameters were calculated relative to the background fluorescence caused by a colored dissolved organic substance (CDOM). To estimate CDOM fluorescence the seawater samples were filtered through a nucleopore filter (Sartorius) with a pore size of $0.2 \mu \mathrm{m}$ under vacuum $<0.2 \mathrm{~atm}$. The filters were rinsed preliminary with $\sim 50 \mathrm{ml}$ deionized waters. The assessment of the chlorophyll $a$ concentration $\left(C_{a}\right.$ ) based on fluorescence intensity $F$ suggests $^{1}$ a linear relationship between these parameters:

$$
F=A \cdot C_{a}+b
$$

\footnotetext{
${ }^{1}$ Matorin, D. N., Osipov, V. A. and Rubin, A. B., 2012. Metodika Izmerenij Obiliya i Indikacii Izmeneniya Sostoyaniya Fitoplanktona v Prirodnykh Vodakh Fluorescentnym Metodom. Teoreticheskie i Prakticheskie Aspekty [Methodology for Measuring Abundance and Indicating Changes in the State of Phytoplankton in Natural Waters Using the Fluorescence Method. Theoretical and Practical Aspects]. Moscow: Alteks, 138 p.
} 
where $A$ - the coefficient of proportionality between the $F$ and the $C_{a} ; b$ - the coefficient corresponding to the background fluorescence, mainly caused by CDOM. This type of dependence between the $F$ and the $C_{a}$ (equation 6) corresponds to the case of CDOM constant concentration. Based on the CDOM light absorption data, it can be concluded that the content of this optically active component in the Black Sea significantly changes during the year. Moreover, for a particular season, the variability of this parameter is characteristic with a change in both depth and distance from the coast [19-21]. Therefore, in our studies, the CDOM fluorescence $F$ was measured in all samples, which was subtracted from the initial measurement to obtain fluorescence associated only with phytoplankton. As a result, the dependence of fluorescence on the chlorophyll $a$ concentration (6) takes the following form

$$
F=A \cdot C_{a},
$$

where $A$ is the coefficient equal to specific (normalized to $C_{a}$ ) fluorescence $F^{*}$.

\section{Chlorophyll a concentration}

\section{Results}

In the research area (Fig. 1) at the end of October 2017, the surface water temperature was $16-18{ }^{\circ} \mathrm{C}$ (Fig. 2). The UML varied between stations from 12 to $20 \mathrm{~m}$. The TC was recorded in the $12-25 \mathrm{~m}$ layer at almost all stations, with the exception of the last two ones in the cruise (stations 21 and 19), which were worked at after the storm. The $Z_{\text {eu }}(1 \%$ PAR) varied between stations within 30$38 \mathrm{~m}$. Values of $0.1 \%$ PAR was observed at 50-57 m depths. For fluorescence vertical distribution a maximum located near the bottom of the euphotic zone (1\% PAR) was typical for almost all the stations.

The relative content of phaeopigments (relative to from value) was in a range 0-18\%. It should be noted that relative concentration of the phaeopigment exceeded $10 \%$ at, and only at the lower horizons depths, where PAR was less than $1 \%$ of the sea surface PAR value. Due to the low content of phaeopigments, the chlorophyll $a$ concentration $C_{a}$ was used in the present research. Typical profiles of the vertical distribution of chlorophyll $a$ concentration $C_{a}$ are presented in Fig. 2. Distribution of $C_{a}$ was almost uniform in the UML (Fig. 2). However, between stations the value $C_{a}$ in the UML varied almost twice - from 0.56 to $0.96 \mathrm{mg} \cdot \mathrm{m}^{-3}$, being equal to $0.78 \pm 0.11 \mathrm{mg} \cdot \mathrm{m}^{-3}$ on average for the sea area under study. At many stations in the TC layer, an increase in the chlorophyll $a$ concentration from 0.7 to $1.01 \mathrm{mg} \cdot \mathrm{m}^{-3}$ (an average of $0.88 \pm 0.1 \mathrm{mg} \cdot \mathrm{m}^{-3}$ ) was noted. Maximum in the profile $C_{a}$ was observed at depth of $1 \%$ of the sea surface PAR. In the maximum the $C_{a}$ values were in the range from 0.89 to $1.2 \mathrm{mg} \cdot \mathrm{m}^{-3}$ and was equal to $1.0 \pm$ $0.12 \mathrm{mg} \cdot \mathrm{m}^{-3}$ on average. 


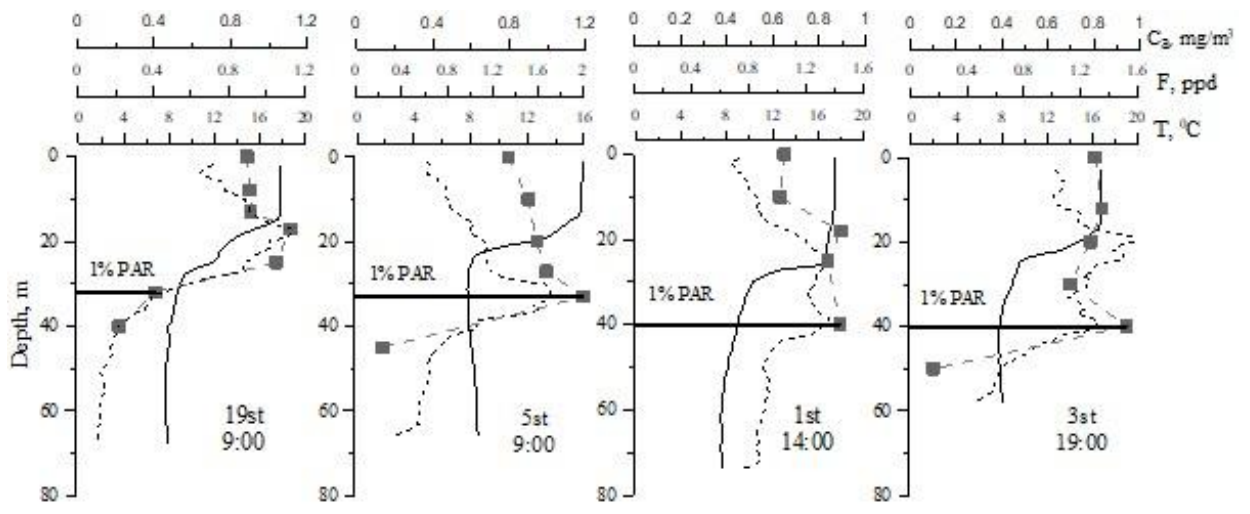

F i g. 2. Profile of temperature vertical distribution $(T)$ (solid line), fluorescence intensity $(F)$ (dotted line) and chlorophyll $a$ concentration $\left(C_{a}\right)$ (grey squares) at separate stations in various periods of a light day, October, 2017

The type of vertical distribution of the chlorophyll $a$ concentration, temperature and fluorescence $F$ allowed designating four layers: the first is the UML, the second is TC, the third is between TC and depth of $1 \%$ of the sea surface PAR and the fourth is between depths of 1 and $0.1 \%$ of the surface PAR. The dependence of fluorescence on the chlorophyll $a$ concentration was estimated for both all data set and particular layers (Fig. 3). It was found out that for all data set (for whole water layer investigated), this dependence was generally described by the following equations:

$$
\begin{gathered}
F_{0}=0,24 C_{a}, \quad r^{2}=0,97, \\
F_{\mathrm{m}}=0,64 C_{a}, \quad r^{2}=0,98 .
\end{gathered}
$$

From the graphs in Fig. 3 it is seen that the obtained dependencies of $F$ on $C_{a}$ (8) - (9) overestimate the values in the $3^{\text {rd }}$ and $4^{\text {th }}$ layers located deeper than the TC and underestimate - in the $1^{\text {st }}$ layer (UML). Therefore, for each of the layers selected, the values of coefficient $A$ were calculated from equation (7), given in Tab.1.

The coefficient $A$ decreases with depth within the water column (Tab. 1). At that, the value of the coefficient $A$ decreases by $10-20 \%$ in the upper three layers and it decreases most sharply in the $4^{\text {th }}$ layer. In fact, the change in the coefficient $A$ reflects a decrease in the chlorophyll $a$ specific fluorescence intensity $\left(\mathrm{F}^{*}=\mathrm{F} / \mathrm{Ca}\right)$ with depth. It should be noted that the correlation $\left(r^{2}\right)$ between $F$ and $C_{a}$ was high (Tab. 1). The value $r^{2}$ was the largest for the dependence $F_{m}$, which is explained by higher values of $F_{m}$ and, as a consequence, a smaller error introduced. 

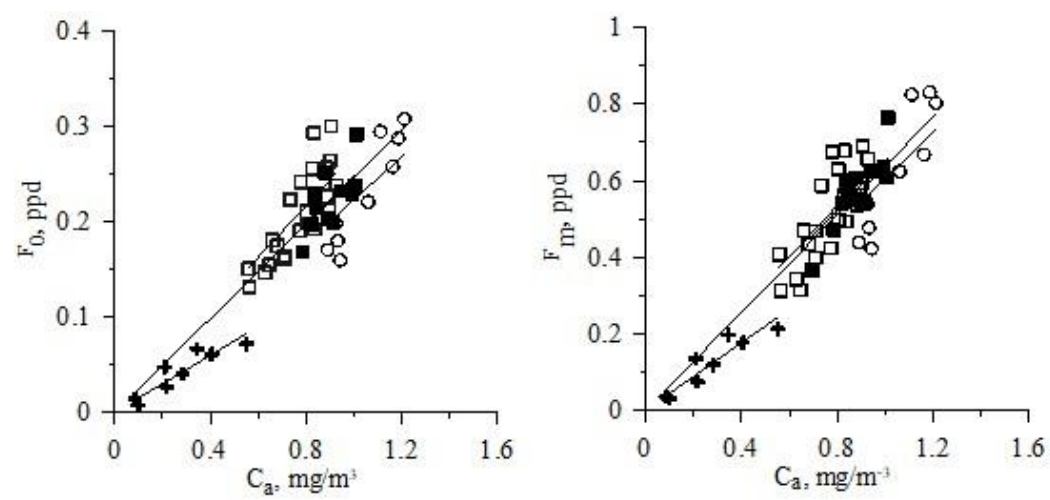

F i g. 3. Comparison of the measured values of the chlorophyll $a$ concentration $\left(C_{a}\right)$ with intensity of chlorophyll $a$ fluorescence $\left(F_{0}\right.$ and $F_{\mathrm{m}}$ ) for the water layers designated in October, 2017: the upper mixed layer $(\square)$, the temperature stratification layer $(\boldsymbol{\square})$, the layers between the temperature stratification layer and the depth of $1 \%$ of the sea surface photosynthetic available radiation (PAR) (०) and layer between the depth of 1 and $0.1 \%$ of the surface PAR (+)

Table 1

\section{Coefficient $A$ of dependence of the constant $\left(F_{0}\right)$ and maximum $\left(F_{\mathrm{m}}\right)$ fluorescence intensity on the chlorophyll $a$ concentration and the correlation coefficient $\left(r^{2}\right)$ in the water layers}

\begin{tabular}{l|c|c|c|c|c}
\hline \multirow{2}{*}{ Layer } & \multicolumn{2}{|c|}{ Coefficient $A$} & \multicolumn{2}{|c|}{$r^{2}$} & \multirow{2}{*}{$\begin{array}{c}\text { Number of } \\
\text { data pairs, } n\end{array}$} \\
\cline { 2 - 5 } & $F_{\mathrm{m}}$ & $F_{0}$ & $F_{\mathrm{m}}$ & $F_{0}$ & 21 \\
\hline 1. Upper mixed layer & 0.67 & 0.27 & 0.98 & 0.98 & 11 \\
\hline 2. Thermocline & 0.66 & 0.25 & 0.99 & 0.99 & \\
\hline $\begin{array}{l}\text { 3. Layer between the thermocline and } \\
\text { the depth of 1\% of the sea surface } \\
\text { PAR }\end{array}$ & 0.61 & 0.22 & 0.98 & 0.98 & 9 \\
$\begin{array}{l}\text { 4. Layer between the depths of the 1 } \\
\text { and 0.1\% of the sea surface PAR }\end{array}$ & 0.45 & 0.16 & 0.95 & 0.91 & 8 \\
\hline
\end{tabular}

Light absorption by phytoplankton pigments

The value of the $a_{\mathrm{ph}}(\lambda)$ coefficient at $455 \mathrm{~nm}\left(a_{\mathrm{ph}}(455)\right)$, corresponding to the wavelength of fluorescence excitation in the MEGA-25 fluorimeter [22], varies depending on the chlorophyll $a$ concentration (Fig. 4). The relationship between these parameters is described by a power function [8]

$$
a_{\mathrm{ph}}(455)=A(455) \cdot C_{a}{ }^{B(455)} \text {. }
$$

For the whole water column under the study (for the four selected layers generally), the equation (10) has the form as follows:

$$
a_{\mathrm{ph}}(455)=0,045 C_{a}^{1.2} \text {. }
$$




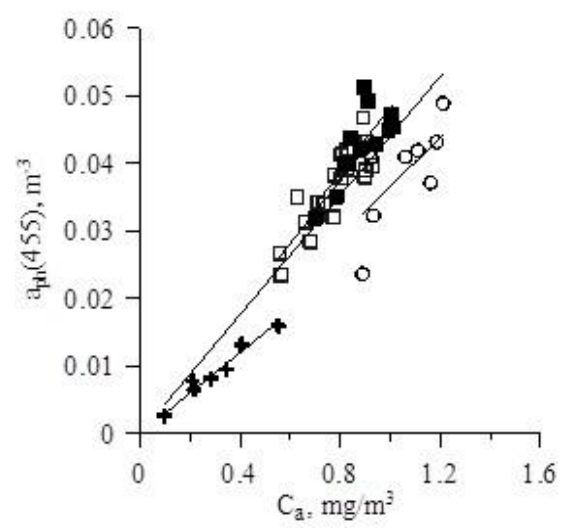

F i g. 4. Dependence of the phytoplankton pigments light absorption coefficient at the wavelength $\sim 455 \mathrm{~nm}\left(a_{\mathrm{ph}}(455)\right)$ on the chlorophyll $a$ concentration $\left(C_{a}\right)$ for the layers distinguished in October, 2017 (symbols are the same as in Fig. 3)

The coefficient $A(455)$ was obtained as $0.045 \mathrm{~m}^{2} \cdot \mathrm{mg}^{-1}$. In fact, this coefficient corresponds to the chlorophyll a specific (normalized to $C_{a}$ ) coefficient of light absorption by phytoplankton pigments at $455 \mathrm{~nm}$ wavelength $\left(a_{\mathrm{ph}}^{*}(455)\right)$ in the case when $C_{a}$ is equal to $1 \mathrm{mg} \cdot \mathrm{m}^{-3}$. The coefficient $a_{\mathrm{ph}}^{*}(455)$ will increase with $C_{a}$ growth if the power-law coefficient $B(455)$ in equation (10) is higher than 1 , or decrease if $B(455)$ is less than 1 .

The relationship between coefficients $a_{\mathrm{ph}}(455)$ and $C_{a}$ was investigated for each designated layer. The coefficients $A(455)$ and $B(455)$ of the dependence described by equation (10) obtained for each layer are presented in Tab. 2.

T a ble 2

Coefficients $A(455)$ and $B(455)$ in the dependence equation (10)
and the correlation coefficient $\left(r^{2}\right)$ in the water layers

\begin{tabular}{l|c|c|c|c}
\hline \multicolumn{1}{c|}{ Layer } & $A(455)$ & $B(455)$ & $r^{2}$ & $\begin{array}{c}\text { Number of } \\
\text { data pairs, } n\end{array}$ \\
\hline 1. Upper mixed layer & 0.047 & 0.99 & 0.78 & 21 \\
\hline $\begin{array}{l}\text { 2. Thermocline } \\
\begin{array}{l}\text { 3. Layer between the thermocline and the } \\
\text { depth of 1\% of the sea surface PAR }\end{array}\end{array}$ & 0.048 & 0.93 & 0.61 & 11 \\
\hline $\begin{array}{l}\text { 4. Layer between the depths of the 1 and } \\
\text { 0.1\% of the sea surface PAR }\end{array}$ & 0.031 & 1.01 & 0.97 & 8 \\
\hline
\end{tabular}


The value of coefficient $A(455)$ decreases with depth from the $1^{\text {st }}$ to the $4^{\text {th }}$ layer by $\sim 35 \%$ (Tab. 2). The value of the power-law coefficient $B(455)$ is close to 1 in almost all layers, with the exception of the $3^{\text {rd }}$ layer. Taking into account the type of relationship between $\left(a_{\mathrm{ph}}(455)\right)$ and $C_{a}$ (equation 10), it was found out that for the range of variability of chlorophyll $a$ concentration $C_{a}$ noted in each layer, the $a_{p h}^{*}(455)$ value remained almost unchanged and equal to coefficient $A(455)$. The $a_{p h}^{*}(455)$ values had a significant difference $(\sim 35 \%)$ between the layers due to a decrease in $A(455)$ coefficient from the $1^{\text {st }}$ to the $4^{\text {th }}$ layer (Tab. 2).

Relationship between fluorescence intensity and phytoplankton pigments light absorption coefficient

The values of the phytoplankton light absorption coefficient normalized to the chlorophyll $a$ concentration $a_{\mathrm{ph}}^{*}(455)$ and fluorescence $F_{\mathrm{m}}^{*}, F_{0}^{*}$ decreased with depth from 0.047 to $0.031 \mathrm{~m}^{2} \mathrm{mg}^{-1}$ and from 0.67 to $0.45 \mathrm{mg}^{-1}$, from 0.27 to $0.16 \mathrm{mg}^{-1}$, respectively (Tab. 3). A comparison of the depth-dependent variability in these parameter revealed the coincidence in their vertical distribution type.

T a ble 3

Coefficient $A(455)$ in equation (10) corresponding to the chlorophyll a specific phytoplankton pigments light absorption coefficient at the wavelength $455 \mathrm{~nm}$ $\left(a_{\mathrm{ph}}^{*}(455)\right)$, and coefficient $\boldsymbol{A}$ corresponding to the specific fluorescence $\left(F_{\mathrm{m}}^{*}\right.$ and $\left.F_{0}^{*}\right)$ in the water layers

\begin{tabular}{|c|c|c|c|}
\hline \multirow[t]{2}{*}{ Layer } & \multirow{2}{*}{$\frac{\begin{array}{c}A(455), \\
\mathrm{m}^{2} \mathrm{mg}^{-1}\end{array}}{a_{\mathrm{ph}}^{*}}$} & \multicolumn{2}{|c|}{$\begin{array}{c}A, \\
\mathrm{mg}_{-}{ }^{1}\end{array}$} \\
\hline & & $F_{\mathrm{m}}^{*}$ & $F_{0}^{*}$ \\
\hline 1. Upper mixed layer & 0.047 & 0.67 & 0.27 \\
\hline 2. Thermocline & 0.048 & 0.66 & 0.25 \\
\hline $\begin{array}{l}\text { 3. Layer between the thermocline and the } \\
1 \% \text { of the sea surface PAR }\end{array}$ & 0.036 & 0.61 & 0.22 \\
\hline $\begin{array}{l}\text { 4. Layer between the depths of the } 1 \text { and } \\
0.1 \% \text {-PAR penetration }\end{array}$ & 0.031 & 0.45 & 0.16 \\
\hline
\end{tabular}

The fluorescence intensity $F_{m}$ and $F_{0}$ were measured on a laboratory fluorimeter with a constant exciting light intensity. As result, the PAR value in equation (1) is taken constant. It should be noted that there are no closed RCs remaining after dark adaptation of phytoplankton carried out before measuring fluorescence $F_{0}$. The reabsorption coefficient $Q_{a}^{*}$ can be neglected. Taking into account three statements mentioned above, the equation (1) will have the following form for $F_{0}$ :

$$
F_{0}=C_{a} \cdot a_{\mathrm{ph}}^{*}(455) \cdot \varphi_{\mathrm{F}} .
$$


The equation (12) is transformed by dividing by $C_{a}$ into:

$$
F_{0}^{*}=a_{\mathrm{ph}}^{*}(455) \cdot \varphi_{\mathrm{F}} \text {. }
$$

Using the values of $a_{\mathrm{ph}}^{*}(455)$ and $F_{0}^{*}$ (Tab. 3), obtained on average for each layer, the values of $\varphi_{\mathrm{F}}$ were calculated. In the first layer $\varphi_{\mathrm{F}}$ was 5.7; in the second 5.1 ; in the third -6.1 and in the fourth -5.1 .

\section{Discussion}

The obtained relationships between the chlorophyll $a$ concentration $C_{a}$ and the phytoplankton pigments light absorption coefficient $a_{\mathrm{ph}}(\lambda)$ is consistent with the previously noted type and degree of change with depth, obtained on the basis of long-term biooptical investigations in the Black Sea [11, 23]. Along with this, the fluorescence intensity $F$ is directly dependent on $a_{\mathrm{ph}}^{*}(\lambda)$ (equation (1)). These results (relationships and regularities) justify the depth-dependent variability in the coefficient $(A)$ of link between $F$ and $C_{a}$ within euphotic layer of the sea.

In the period of seasonal stratification of waters, provided that the thermocline is located within the euphotic zone, the ratio between fluorescence and chlorophyll $a$ concentration varies with depth. Due to the acclimation of the phytoplankton community to the main environmental factors (temperature, nutrient availability and light intensity), the intracellular concentration of pigments and the ratio between them change, which leads to change of $a_{\mathrm{ph}}^{*}(\lambda)[7,24,25]$. At the same time, with the adaptation of the phytoplankton community to changing conditions, the species composition of the community changes and, as a result, the pigment complex and the size structure of the phytoplankton community change. This is manifested in a change in the spectrum shape and the values of the $a_{\mathrm{ph}}^{*}(\lambda)$ coefficients [8, 23].

The obtained results showed that the use of a constant coefficient of the link between $C_{a}$ and $F$ (for the upper euphotic layer of the sea) in the Black Sea will lead to at least a $40 \%$ error in estimating the chlorophyll $a$ concentration $\left(C_{a}\right)$ based on the fluorescence data $(F)$. The error is mainly $(\sim 88 \%)$ due to the variability of the phytoplankton ability to absorb light quanta per unit of chlorophyll $a\left(a_{\mathrm{ph}}^{*}(\lambda)\right)$. It should be noted that during the period of the research (October) the values of the PAR incident on the sea surface were less than its summer values [26, 11], and the UML was deeper than in summer period. The UML thickness and light conditions in this layer vary from the moment of formation of seasonal stratification of waters (late spring) to the UML deepening period (late autumn), which is associated with the annual solar insolation cycle of the sea [26] and the ratio between the UML and $Z_{\text {eu }}$ thickness. Such changes lead to the fact that the intracellular concentration in the phytoplankton existing in the UML increases the proportion of accessory pigments decreases with a decrease in the average photosynthetic available radiation within the UML [24]. The noted changes in the pigment content in microalgae cells are accompanied by a decrease in $a_{\mathrm{ph}}^{*}(\lambda)$ values $[7,25]$. Earlier, in [11], these parameters were compared in 
the UML of deep-water part of the Black Sea during the winter and summer periods, which showed an almost 3-fold difference in the values in the blue part of the spectrum (at $~ 440 \mathrm{~nm}$ ).

Taking into account the influence of the UML thickness and the solar insolation of the sea surface on the value $a_{\mathrm{ph}}^{*}(\lambda)$ in the UML, the degree of depthdependent variability of $a_{\mathrm{ph}}^{*}(\lambda)$ will change during the period of seasonal water stratification. It should be noted that the vertical variability $a_{\mathrm{ph}}^{*}(\lambda)$ will be maximum at the beginning of summer, when the maximum solar activity and the minimum thickness of the UML coincide in time, and the PAR value on average for the UML reaches $1000 \mu \mathrm{E} \cdot \mathrm{m}^{-2} \cdot \mathrm{s}^{-1}$ [27]. As a result, both the coefficient $A$ in equation (7), which describes the relationship of $F$ with $C_{a}$ in the UML, and its change with depth in the euphotic layer will be maximum at the beginning of the summer period.

\section{Conclusions}

The vertical variability of the relationship between the chlorophyll $a$ concentration and its fluorescence during the period of seasonal waters stratification is shown. Four different water layers were identified within euphotic layer based on vertical distribution of the fluorescence intensity, temperature and photosynthetic available radiation. It was shown that using a constant coefficient of link between $C_{a}$ and $F$ (for the entire upper productive layer) in the Black Sea will lead to at least $40 \%$-error in the $C_{a}$ estimation based on $F$.

Due to the noted inconsistency of the relationship between the chlorophyll $a$ concentration and its fluorescence, as well as the significant influence of environmental conditions on the relationship between the chlorophyll $a$ concentration and the ability of phytoplankton to absorb solar quanta, it is planned to carry out further studies to estimate the chlorophyll $a$ concentration based on the fluorescence data measured using BioArgo floats.

\section{REFERENCES}

1. Lorenzen, C.J., 1966. A Method for the Continuous Measurement of in vivo Chlorophyll Concentration. Deep Sea Research and Oceanographic Abstracts, [e-journal] 13(2), pp. 223227. https://doi.org/10.1016/0011-7471(66)91102-8

2. Kiefer, D.A., 1973. Fluorescence Properties of Natural Phytoplankton Populations. Marine Biology, [e-journal] 22(3), pp. 263-269. https://doi.org/10.1007/BF00389180

3. Xing, X., Morel, A., Claustre, H., Antoine, D., D'Ortenzio, F., Poteau, A. and Mignot, A., 2011. Combined Processing and Mutual Interpretation of Radiometry and Fluorimetry from Autonomous Profiling Bio Argo Floats: Chlorophyll a Retrieval. Journal of Geophysical Research: Oceans, [e-journal] 116(C6). C06020. https://doi.org/10.1029/2010JC006899

4. Kopelevich, O.V., Burenkov, V.I., Ershova, S.V., Sheberstov, S.V. and Evdoshenko, M.A., 2004. Application of SeaWiFS Data for Studying Variability of Bio-Optical Characteristics in the Barents, Black and Caspian Seas. Deep-Sea Research Part II: Tropical Studies in Oceanography, [e-journal] 51(10-11), pp. 1063-1091. https://doi.org/10.1016/j.dsr2.2003.10.009

5. Schmechtig, C., Poteau, A., Claustre, H., D'Ortenzio, F. and Boss, E., 2015. Processing BioArgo Chlorophyll-A Concentration at the DAC Level. https://doi.org/10.13155/39468

6. Babin, M., 2008. Phytoplankton Fluorescence: Theory, Current Literature and in situ Measurement. In: M. Babin, C. S. Roesler, J. J. Cullen, eds., 2008. Real-Time Coastal Observing Systems for Marine Ecosystem Dynamics and Harmful Algal Blooms: 
Theory, Instrumentation and Modelling. Paris: UNESCO Publishing, pp. 237-280. Available at: https://unesdoc.unesco.org/ark:/48223/pf0000160000 [Accessed: 04 July 2019].

7. Morel, A. and Bricaud, A., 1981. Theoretical Results Concerning Light Absorption in a Discrete Medium, and Application to Specific Absorption of Phytoplankton. Deep-Sea Research Part A: Oceanographic Research Papers, [e-journal] 28(11), pp. 1375-1393. https://doi.org/10.1016/0198-0149(81)90039-X

8. Bricaud, A., Babin, M., Morel, A. and Claustre, H., 1995. Variability in the ChlorophyllSpecific Absorption Coefficients of Natural Phytoplankton: Analysis and Parameterization. Journal of Geophysical Research: Oceans, [e-journal] 100(C7), pp. 13321-13332. https://doi.org/10.1029/95JC00463

9. Falkowski, P. and Kiefer, D.A., 1985. Chlorophyll a Fluorescence in Phytoplankton: Relationship to Photosynthesis and Biomass. Journal of Plankton Research, [e-journal] 7(5), pp. 715-731. https://doi.org/10.1093/plankt/7.5.715

10. Babin, M., Morel, A., Claustre, H., Bricaud, A., Kolber, Z., Falkowski, P.G., 1996. Nitrogenand Irradiance-Dependent Variations of the Maximum Quantum Yield of Carbon Fixation in Eutrophic, Mesotrophic and Oligotrophic Marine Systems. Deep-Sea Research Part I: Oceanographic Research Papers, [e-journal] 43(8), pp. 1241-1272. https://doi.org/10.1016/0967-0637(96)00058-1

11. Churilova, T., Suslin, V., Krivenko, O., Efimova, T., Moiseeva, N., Mukhanov, V. and Smirnova, L., 2017. Light Absorption by Phytoplankton in the Upper Mixed Layer of the Black Sea: Seasonality and Parameterization. Frontiers in Marine Science, [e-journal] 4. Article 90. https://doi.org/10.3389/fmars.2017.00090

12. Vedernikov, V.I., 1989. [Primary Production and Chlorophyll in the Black Sea in the Summer-Fall Season]. In: M. E. Vinogradov and M. V. Flint, eds., 1989. [The Structure and Production Characteristics of Plankton Communities in the Black Sea]. Moscow: Nauka, pp. 65-83 (in Russian).

13. Lorenzen, C.J., 1967. Determination of Chlorophyll and Pheo-Pigments: Spectrophotometric Equations. Limnology and Oceanography, [e-journal] 12(2), pp. 343-346. https://doi.org/10.4319/lo.1967.12.2.0343

14. Mitchel, B.G., Kahru, M., Wieland, J. and Stramska, M., 2002. Determination of Spectral Absorption Coefficients of Particles, Dissolved Material and Phytoplankton for Discrete Water Samples. In: J. L. Mueller and G. S. Fargion, eds., 2002. Ocean Optics Protocols for Satellite Ocean Color Sensor Validation, Revision 3, Volume 2. Greenbelt, Maryland: Goddart Space Flight Center, pp. 231-257.

15. Yentsch, C.S., 1962. Measurement of Visible Light Absorption by Particulate Matter in the Ocean. Limnology and Oceanography, [e-journal] 7(2), pp. 207-217. https://doi.org/10.4319/1o.1962.7.2.0207

16. Mitchell, B.G., 1990. Algorithms for Determining the Absorption Coefficient for Aquatic Particulates Using the Quantitative Filter Technique. In: SPIE, 1990. Proceedings SPIE. Vol. 1302: Ocean Optics X. pp. 137-148. https://doi.org/10.1117/12.21440

17. Tassan, S. and Ferrari, G.M., 1995. An Alternative Approach to Absorption Measurements of Aquatic Particles Retained on Filters. Limnology and Oceanography, [e-journal] 40(8), pp. 1358-1368. https://doi.org/10.4319/lo.1995.40.8.1358

18. Gaevskii, N.A. and Morgun, V.N., 1993. Use of Variable and Delayed Fluorescence to Study Plant Photosynthesis. Russian Plant Physiology, 40(1, part 2), pp. 119-127.

19. Berthon, J.-F., Mélin, F. and Zibordi, G., 2008. Ocean Colour Remote Sensing of the Optically Complex European Seas. In: V. Barale and M. Gade, eds., 2008. Remote Sensing of the European Seas. Dordrecht: Springer, pp. 35-52. https://doi.org/10.1007/978-1-4020-6772-3_3

20. Moiseeva, N.A., Churilova, T.Ya., Efimova, T.V. and Kryvenko, O.V., 2016. Assessment of Chlorophyll a Concentration in The Black Sea Based on Fluorescence. In: D. A. Subetto, ed., 2016. Water Resources: Research and Management (Limnological school and workshop). Proceedings of the 5th International Young Scientists Conference (5-8 September 2016, Petrozavodsk). Vol. 1. Petrozavodsk: Karelian Research Centre of RAS publishers, pp. 305-313 (in Russian).

21. Churilova, T., Moiseeva, N., Efimova, T., Suslin, V., Krivenko, O. and Zemlianskaia, E., 2017. Annual Variability in Light Absorption by Particles and Colored Dissolved Organic Matter in the Crimean Coastal Waters (the Black Sea). In: SPIE, 1990. Proceedings SPIE. Vol. 10466: 23rd International Symposium on Atmospheric and Ocean Optics: Atmospheric Physics. 104664B. https://doi.org/10.1117/12.2288339 
22. Pogosyan, S.I., Galchuk, S.V., Kazimirko, Y.V., Konyukhov, I.V. and Rubin, A.B., 2009. Application of Fluorimeter "Mega-25" to Estimate the Quantity of Phytoplankton and Assess Its Photosynthetic Status. Water: Chemistry and Ecology, (6), pp. 34-40 (in Russian).

23. Churilova, T., Suslin, V., Sosik, H.M., Efimova, T., Moiseeva, N., Moncheva, S., Mukhanov, V., Rylkova, O. and Krivenko, O., 2019. Phytoplankton Light Absorption in the Deep Chlorophyll Maximum Layer of the Black Sea. European Journal of Remote Sensing, [ejournal] 52(sup. 1), pp. 123-136. https://doi.org/10.1080/22797254.2018.1533389

24. MacIntyre, H.L., Kana, T.M., Anning, T. and Geider, R.J., 2002. Photoacclimation of Photosynthesis Irradiance Response Curves and Photosynthetic Pigments in Microalgae and Cyanobacteria. Journal of Phycology, [e-journal] 38(1), pp. 17-38. https://doi.org/10.1046/j.1529-8817.2002.00094.X

25. Fujiki, T. and Taguchi, S., 2002. Variability in Chlorophyll a Specific Absorption Coefficient in Marine Phytoplankton as a Function of Cell Size and Irradiance. Journal of Plankton Research, [e-journal] 24(9), pp. 859-874. doi:10.1093/plankt/24.9.859

26. Suslin, V.V., Korolev, S.N., Kucheryaviy, A.A., Churilova, T.Ya. and Krivenko, O.V., 2015. Photosynthetically Available Radiation on Surface of the Black Sea Based on Ocean Color Data. In: SPIE, 1990. Proceedings SPIE. Vol. 9680: 21st International Symposium Atmospheric and Ocean Optics: Atmospheric Physics. 96800T. https://doi.org/10.1117/12.2203660

27. Churilova, T.Ya. and Suslin, V.V., 2012. On Causes of Emiliania Huxleyi Domination in Phytoplankton of Deep Waters Part of the Black Sea in Early Summer. In: MHI, 2012. Ecological Safety of Coastal and Shelf Zones and Comprehensive Use of Shelf Resources. Sevastopol: ECOSI-Gidrofizika. Iss. 26, vol. 2, pp. 195-203 (in Russian).

About the authors:

Nataliya A. Moiseeva - Junior Research Associate, A.O. Kovalevsky Institute of Biology of the Southern Seas (2 Nakhimov Sq., Sevastopol, 299011, Russian Federation), ORCID ID: 0000-0003-1356-7981, Scopus Author ID: 57194431032, Author ID 959717 SPIN-код 8946-3315, nataliya-moiseeva@yandex.ru

Tatiana Ya. Churilova - Leading Research Associate, Head of Geomatics Research Center, A.O. Kovalevsky Institute of Biology of the Southern Seas of RAS (2 Nakhimov Sq., Sevastopol, 299011, Russian Federation), Ph. D. (Biol.), ORCID ID: 0000-0002- 0045-7284, Scopus Author ID: 6603622802, ResearcherID: O-8437-2016, AuthorID 88856 SPIN-код 2238-9533, tanya.churilova@gmail.com

Tatiana V. Efimova - Junior Research Associate, A.O. Kovalevsky Institute of Biology of the Southern Seas of RAS (2 Nakhimov Sq., Sevastopol, 299011, Russian Federation), ORCID ID: 0000-0003-3908-4160, Scopus Author ID: 57194423783, AuthorID: 766926 SPIN-код: 1668-0742, tatyana-iefimova@yandex.ru

Olga V. Krivenko - Senior Research Associate, A.O. Kovalevsky Institute of Biology of the Southern Seas of RAS, (2 Nakhimov Sq., Sevastopol, 299011, Russian Federation), Ph. D. (Biol.), ORCID ID: 0000-0001- 6292-5293, Scopus Author ID: 6602415951, ResearcherID: 0-8541-2016, AuthorID: 933995 SPIN-код: 1828-7516, olkrivenko@gmail.com

Dmitriy N. Matorin - Leading Research Associate, Lomonosov Moscow State University (1 Leninskie Gory, Moscow, 119991, Russian Federation), D. Sci. (Biol.), Professor, ResearcherID: S-5443-2016, Scopus Author ID: 6701647993, matorin@ biophys.msu.ru

Contribution of the authors:

Nataliya A. Moiseeva - preparation of the article text, collection of materials, data processing and analysis of the results

Tatiana Ya. Churilova - the problem statement, preparation of the article text

Tatiana V. Efimova - collection of materials, data processing, preparation of graphic materials

Olga V. Krivenko - preparation of the article text, consultations on the article topic

Dmitriy N. Matorin - preparation of the article text, consultations on the topic of the article

All authors have read and approved the final manuscript.

The authors declare that they have no conflict of interest. 